\title{
Effect of Temperature and Time on Nickel Aluminide Coating Deposition
}

\author{
ALI DAD CHANDIO*, AND SHAHID HUSSAIN ABRO* \\ RECEIVED ON 18.01.2017 ACCEPTED ON 21.08.2017
}

\begin{abstract}
The $\beta$ NiAl coating was deposited onto Nickel based CMSX-4 superalloy by in-situ CVD (Chemical Vapor Deposition) method. Main focus of this contribution was to study the influence of aluminizing time and temperature on the microstructure and thickness of the coating; this was followed by examination by XRD (X-Ray Diffraction), electron microscope. Results suggest that an incremental variation in temperature alters the coating activities from HA(High Activity) to LA(Low Activity). This is exhibited by the resultant CT (Coating Thickness) since HA coatings are thicker than LA counterparts. The microstructure of the coating formed at low temperature (or HA ones) showed a large amount of $\alpha$-Cr precipitates while one formed at high temperature (or LA ones) exhibited lower amounts of such precipitates. Moreover, incremental aluminizing time showed linear trend of CT at initial stage, thereafter $(10 \mathrm{hrs})$ it leveled off. Whereas it does not affect microstructure of the coating.
\end{abstract}

Key Words: In-Situ Chemical Vapor Deposition, Coating Thickness, High Activity and Low Activity, Temperature and Time.

\section{INTRODUCTION}

$\mathrm{T}$

BC (Thermal Barrier Coating) is applied onto turbine blades of aeroengine as to reduce their

surface temperatures and enhance engine working efficiency. TBC is a multilayered system i.e. topcoat, thermally grown oxide and $\mathrm{BC}$ (Bond Coat or Bond Coating). The performance of TBC is highly influenced by BC. One of the aspects to produce good quality coating is the proper control over processing parameters. Moreover, TBC is widely applied for thermal insulation of aeroengine turbine blades [1]. The ultimate goal of such system is to reduce turbine surface temperature in order to improve component life span and working efficiency of aeroengines. One of the most commonly adopted BCs in TBC is nickel aluminide ( $\beta \mathrm{NiAl})$. It has an ordered $\mathrm{B} 2$ structure, high melting point, low density, and enhanced resistance to oxidation [2]. One of the key aspects to produce improved quality coatings (i.e. optimum CT and microstructure) is the control and optimization of temperature and time. Nevertheless, there are numerous techniques that are applied used to produce $\beta \mathrm{NiAl}$ coatings such as; insitu CVD, physical vapor deposition and vapor phase CVD etc. However, the method of economic choice is the in-situ CVD. Yet again, coating thickness and 
microstructure are critical factors in this method which needs optimization. Because, it has been reported in vapor phase CVD method that the coating quality depends on the processing factors [3].

Similar study was also carried out by Tong, et. al. [4] the authors studied the low temperature formation mechanism of the nickel aluminide coatings. The concluded huge impact of varying the pack parameters on the coating thickness except the activator i.e. ammonium chloride $\left(\mathrm{NH}_{4} \mathrm{Cl}\right)$. However, the microstructure remained unaffected in their study [4]. Moreover, the nature of formation was suggested to be diffusion controlled [4-6].

On contrary, this research is to advance the knowledge of in-situ CVD parameters affecting the coating microstructure. For BC to serve in TBC system its CT plays vital role since it provides aluminum reservoir for protection. This is due to fact that the higher it is, the more is $\mathrm{Al}$ content that is instrumental for improved oxidation. Moreover, this is mandatory in two ways; first the coating microstructure is substrate dependent that relies on coating formation parameters and second the turbine blades thickness is $\sim 1 \mathrm{~mm}$, thus higher CT could deteriorate super alloy mechanical properties [7-8]. Moreover, interestingly in this research it was found that the temperature could change the process activities without changing the pack chemistry. Therefore, such behavior will be instrumental to achieve the desired CT without affecting the process assembly (in particular at lower temperature). However, at higher temperature, extended process time will be detrimental for the mechanical properties of superalloy components without significant increase in CT.

\section{MATERIALS AND METHOD}

Second generation CMSX-4 single crystal superalloy was selected for the formation of $\beta \mathrm{NiAl}$ layers whose chemistry is presented in Table 1. The alloy coupons were given by Rolls Royce Plc, Derby, UK. Alloy samples into 10x10x2 and/or 10x15x2 mm discs were prepared. After sectioning, grinding was carried out using 240-1200 grit SiC papers. Subsequently, substrates were cleaned ultrasonically and dried by using vacuum oven.

These alloy samples were coated at different times and temperatures using an in-situ CVD method. It should be noted that the main raw materials for coating deposition were the $\mathrm{Al}_{2} \mathrm{O}_{3}, \mathrm{NH}_{4} \mathrm{Cl}$ and $\mathrm{Al}$. More details of the aluminizing conditions and procedures are reported elsewhere [9-11]. Once coatings were formed, a final process was applied that is called diffusion annealing at $1150^{\circ} \mathrm{C}$ for 5 hours. In order to characterize the coatings, SEM (Scanning Electron Microscope) (Philips XL30) coupled with EDS and XRD, (Philips X'pert Pan Analytical) were used. The fundamental purpose of characterization was to assess microstructure, chemical composition and coating phase(s).

\section{RESULTS AND DISCUSSION}

\subsection{Coating Cross-Sections}

Fig. 1(a-e) presents the cross-section of the $\beta \mathrm{NiAl}$ along with line profile from top to bottom and XRD spectrum

TABLE 1. THE CHEMICAL COMPOSITION OF CMSX-4 SUPERALLOY (CANNON-MUSKEGON CORPORATION, USA) THAT WAS USED IN THIS STUDY

\begin{tabular}{|c|c|c|c|c|c|c|c|c|c|c|}
\hline & $\mathrm{W}$ & $\mathrm{Ta}$ & $\mathrm{Hf}$ & $\mathrm{Ni}$ & $\mathrm{Mo}$ & $\mathrm{Co}$ & $\mathrm{Al}$ & $\mathrm{Re}$ & $\mathrm{Cr}$ & $\mathrm{Ti}$ \\
\hline At (\%) & 2.0 & 2.2 & 0.03 & 63.8 & 0.4 & 9.2 & 12.6 & 1.0 & 7.6 & 1.3 \\
\hline Weight (\%) & 6.40 & 6.60 & 0.1 & 61.42 & 0.6 & 9.60 & 5.64 & 2.90 & 6.40 & 1.0 \\
\hline
\end{tabular}

Mehran University Research Journal of Engineering \& Technology, Volume 37, No. 4, October, 2018 [p-ISSN: 0254-7821, e-ISSN: 2413-7219] 
depicting the phases. A large number of coating samples were prepared and analyzed randomly as to confirm or validate the deposition process. The coating microstructure comprises of main two layers; outer layer and inner one (an IDZ (Inter-Diffusion Zone)) as shown in Fig. 1(a). Coating contains $\alpha$-Cr precipitates in the magnified micrograph with bright contrast as shown in Fig. 1(b) which is similar to one found elsewhere [12]. Thus, it is the characteristic structure of the coating by low temperature high activity process. Line scan profile of same coating cross-section through the thickness exhibits numerous other elements in the coating i.e. Co,

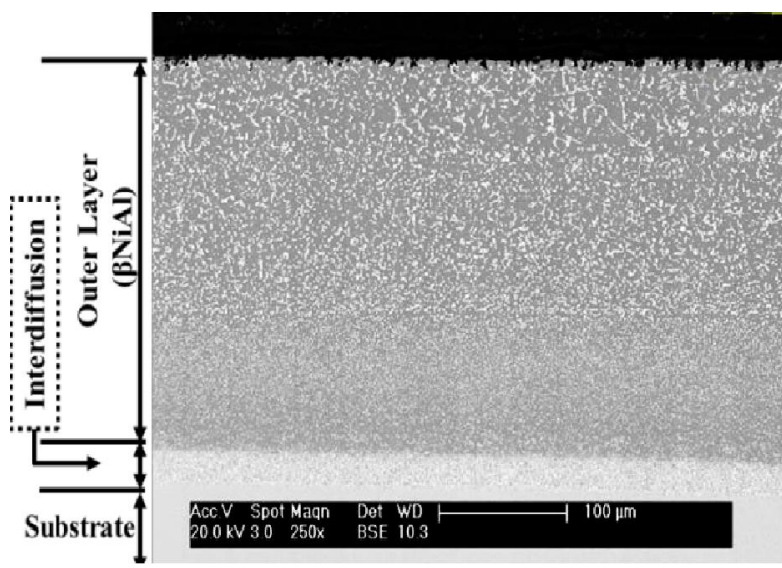

FIG. I(a). THE MICROSTRUCTURE OF HA COATING IN AS RECEIVED CONDITION WHICH EXIBITS THE TYPICAL TWO LAYERED STRUCTURE

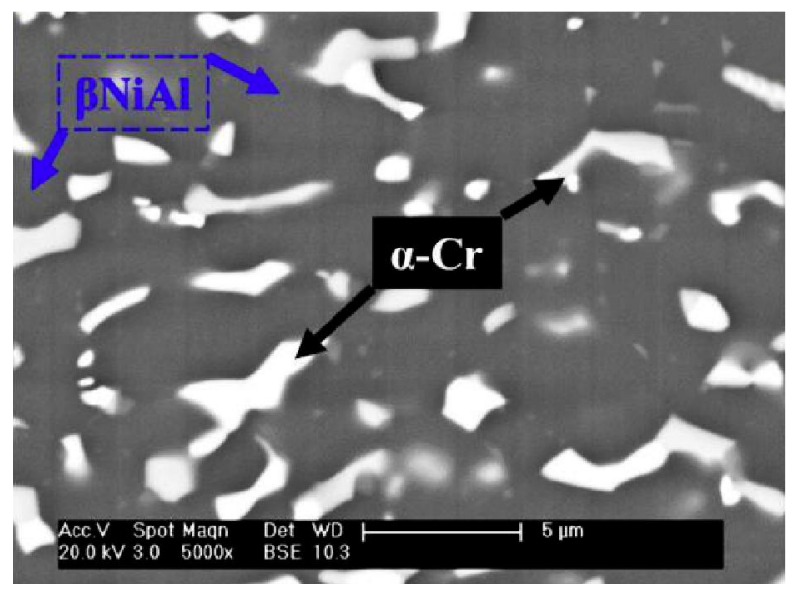

FIG. 1(b). SIMILARLY THE MICROSTRUCTURE AS SHOWN ABOVE (FIG. 1(A)) IS MAGNIFIED AT UPPER LAYER THEREBY EXHIBITING TYPICAL $\alpha$-Cr PRECIPITATES
Cr, W, Ti and Ta. These elements are migrated from substrate into the coating. Furthermore, line profile observed by EDS analysis confirms the 'high activity' nature of coating formed at low temperature as shown in Fig. 1(c).

Fig. 2 shows the microstructure of one of the coatings processed at similar conditions as the coating shown in Fig. 1(a-b) except it was deposited at $1100^{\circ} \mathrm{C}$. Two main differences are visible from cross-sections of both of these coatings; (i) coating processed at $1100^{\circ} \mathrm{C}$ has lower CT and (ii) it contains lower amounts of

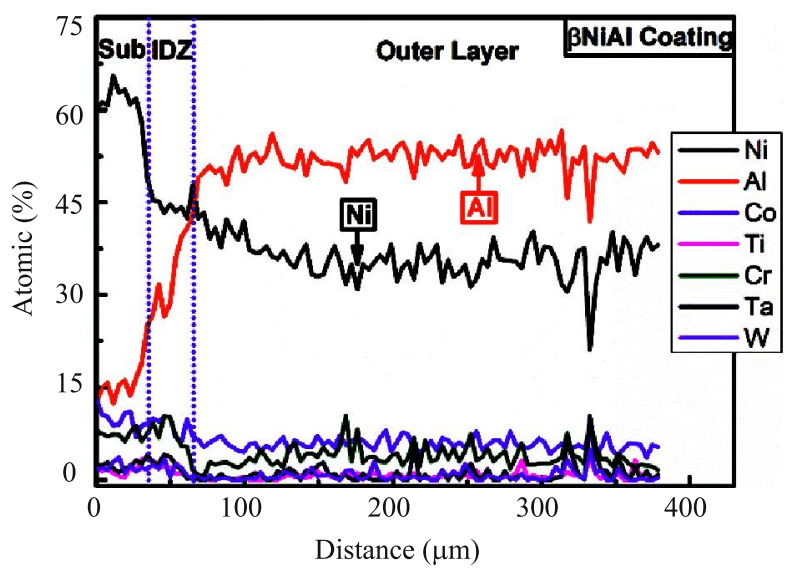

FIG. 1(c). EDS LINE PROFILE SHOWS NUMEROUS SUBSTRATE ELEMENTS IN THE COATING OTHER THAN STANDARD AL AND NI

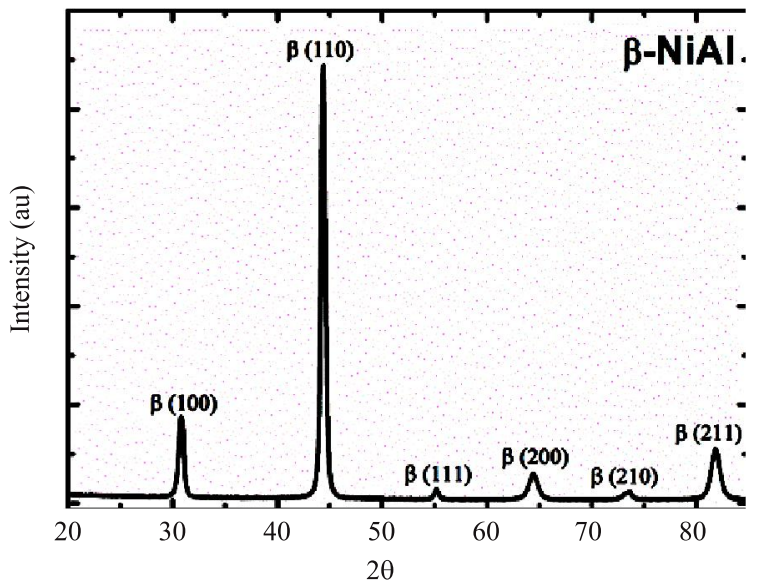

FIG. 1(d). XRD SPECTRUM CONFIRMING bNIAL PHASE OF THESE COATINGS IN THEIR AS RECEIVED FORMS

Mehran University Research Journal of Engineering \& Technology, Volume 37, No. 4, October, 2018 [p-ISSN: 0254-7821, e-ISSN: 2413-7219] 
precipitates in outer layer. This shows that coating activity is changed upon increasing the temperature. This is termed as LA response i.e. coating exhibited LA nature. This will be discussed in detail in next section.

Moreover, the coating phases were also confirmed by $\mathrm{XRD}$ as shown earlier in Fig. 1(d) for both of these coatings. The major phase of these coatings was found to be $\beta \mathrm{NiAl}$. However, it contains the fine distribution of $\alpha$-Cr precipitates (Fig. 1(d)) having overlapping peaks with $\beta$ NiAl phase. Similar coatings were observed elsewhere by using CVD process [13]. In general, SEM and XRD examination demonstrate that coatings deposited are characteristics of HA low temperature method [9]. Thus this clearly indicates that temperature is instrumental for the formation of kind at exactly at same pack chemistry.

\subsection{CT Vs Aluminizing Temperature}

Fig. 3 presents shows the temperature versus CT plot. It should be noted that other coating parameters were kept constant. There is a two stage response of the temperature

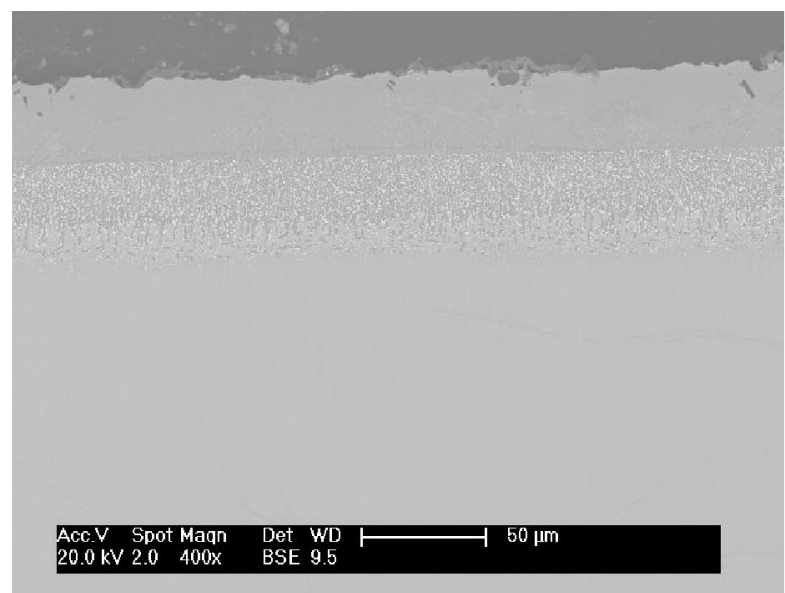

FIG. 2. THE CROSS-SECTION OF THE COATING DEPOSITED AT $1100^{\circ} \mathrm{C}$ WHILE KEEPING ALL PARAMETERS SAME AS ONE SHOWN EARLIER FIG. 1(a-b) observed. First, from $800-950^{\circ} \mathrm{C}$, the CT increased considerably. Second, CT showed variable trend; it increased at initial stage and reduced afterwards, and finally steady state was attained. The only logical inference from this is the change in activities of $\mathrm{Ni}$ and $\mathrm{Al}$. This mean the coating growth phenomenon was changed by the variation of temperature. This confirms the microstructural evolution of the coating as discussed earlier. Indeed, this is due to fact that the coating formed in low temperature range is commonly known to be HA [14]. Because they grow by inward and hence higher CT, whereas, at high temperature (beyond $1000^{\circ} \mathrm{C}$ ), the activity of $\mathrm{Al}$ is reduced and that of $\mathrm{Ni}$ is increased [2]. Hence, the resultant coating is termed as LA. Therefore, the temperature of the in-situ alters the coating growth process, hence activities of $\mathrm{Ni}$ and $\mathrm{Al}$ that are principal diffusing elements in the process [10]. It must be remembered that the HA outcome or yield is always $\delta$ $\mathrm{Ni}_{2} \mathrm{Al}_{3}$ phase. Such phase spreads or penetrates deeper into substrate and hence permitting higher $\mathrm{CT}$ in comparison to LA counterpart (Fig. 1(a-b)). However, to make such phase suitable for oxidation resistance application, a diffusion annealing treatment is carried out

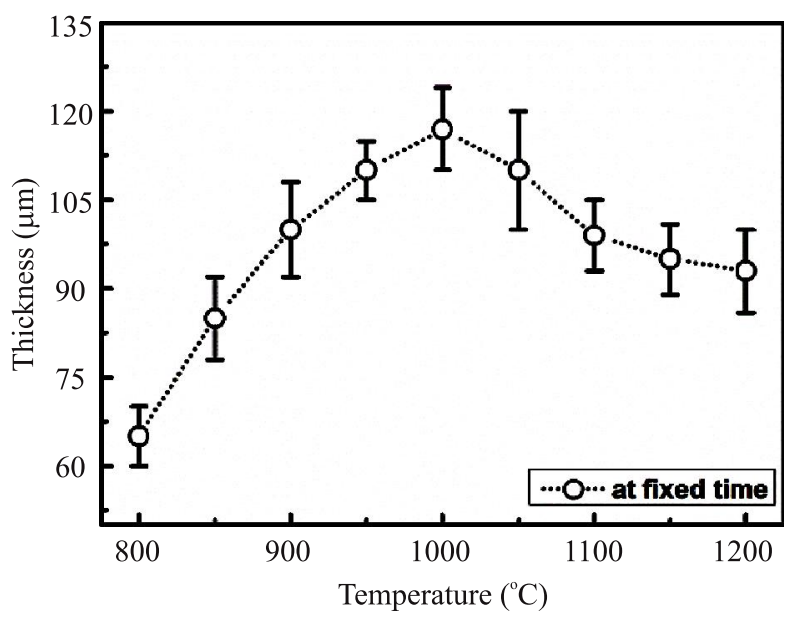

FIG. 3. THE DATA THAT WAS OBTAINED AT DIFFERENT TEMPERATURES TO MEASURE THE CT

Mehran University Research Journal of Engineering \& Technology, Volume 37, No. 4, October, 2018 [p-ISSN: 0254-7821, e-ISSN: 2413-7219] 
in order to convert it into $\beta \mathrm{NiAl}$. On the contrary, LA counterpart coatings are mainly made of $\beta \mathrm{NiAl}$ phase which comparably grow slower (Fig. 2). The coating activities and their thermodynamics have been excellently explained and reported elsewhere [10,14]. So, it emerges that the choice of temperature is an essential parameter to govern the growth process of coating.

\subsection{CT Vs Aluminizing Time}

Fig. 4 shows the coating aluminizing time or coating formation time versus CT plot. It should be noted that other coating parameters were kept constant. It has been found that aluminizing time permits greater control over CT used in aeroengine turbine blades. However, prolonged processing time is detrimental for substrate mechanical properties, since TCP (Topologically Closed Phase) is formed (unpublished data). This results in compromised mechanical properties of alloy for which it is designed. More or less a direct trend between CT and aluminizing time is observed to a certain level under present set of experimental conditions. More detailed examination of the CT trends shows that the CT leveled off after some hours (10 hours). A logical implication of this would be the consumption of activator from coating mixture; hence this is one of drawbacks of in-situ CVD method to that of its vapor phase counterpart [2]. At higher temperature, the activator consumes faster that is noticed for large amount of vapor production consequently lower CT was observed. Therefore, larger duration at high temperature will not increase the CT rather will be detrimental for superalloy components. Because, in vapor phase CVD technique, the CT could be made thicker as desired since it is a continuous process. Indeed, the halide vapors are created in outside reactors continually in vapor phase CVD setup [2].

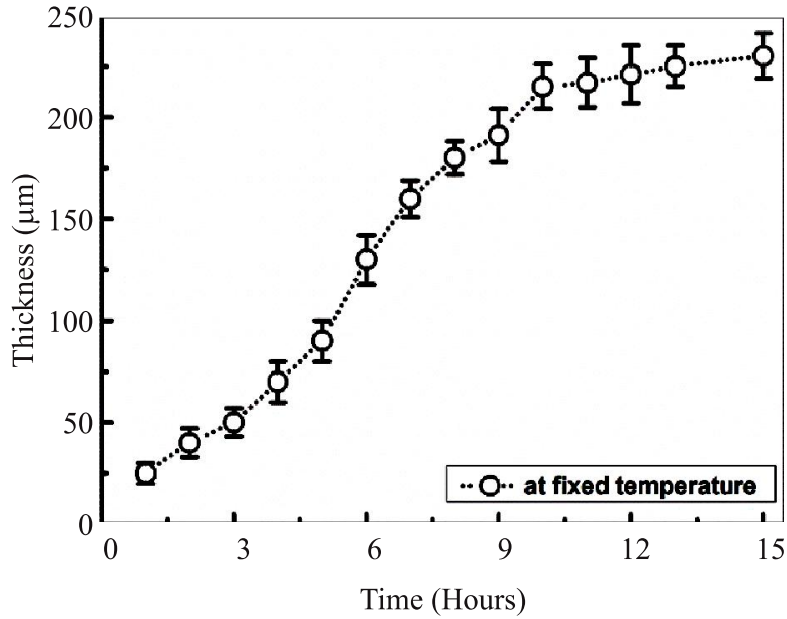

FIG. 4. THE DATA THAT WAS OBTAINED AT DIFFERENT TEMPERATURES TO MEASURE THE CT

\section{CONCLUSION}

In-situ CVD method was used in present study to examine the effect of aluminizing conditions on microstructure and CT. A great number of aluminide coating samples were magnificently prepared onto single crystal CMSX-4 superalloy substrates. Microstructure and CT were monitored in detail. Present results indicated significant influence of temperature on the CT and microstructure. Progressive increase in aluminizing temperature was found to alter coating activities i.e. from HA to LA. This was exhibited by the resultant CT, as the HA coatings were thicker than that of LA counterparts. The microstructure of the coating formed at low temperature (or HA ones) contained the significant amount of $\alpha-\mathrm{Cr}$ precipitates while one formed at high temperature (or LA ones) showed lower amounts of such precipitates. Moreover, at fixed temperature $\left(880^{\circ} \mathrm{C}\right)$; aluminizing time was found to have significant impact on the CT. However, after some time (10 hours), CT leveled off and this was attributed to the consumption of activator from the aluminizing mixture over the time. In addition, no considerable effect of aluminizing time was noticed on the coating microstructure under preset of experimental conditions. However, presumably at higher temperature, the extended time could have detrimental effect on substrate.

Mehran University Research Journal of Engineering \& Technology, Volume 37, No. 4, October, 2018 [p-ISSN: 0254-7821, e-ISSN: 2413-7219] 


\section{ACKNOWLEDGEMENT}

Authors thanks to the University of Manchester, UK and NED University of Engineering \& Technology, Karachi, Pakistan, for their joint funding. Authors wish to thank the Organizing Committee of $2^{\text {nd }}$ National Conference on Metallurgy \& Materials, for providing the platform for oral presentation and publishing the paper in Mehran University Research Journal of Engineering \& Technology.

\section{REFERENCES}

[1] Clarke, D., and Levi, C., "Materials Design for the Next Generation Thermal Barrier Coatings", Annual Review of Materials Research, Volume 33, No. 1, pp. 383-417, 2003.

[2] Bose, S., "High Temperature Coatings", ButterworthHeinemann, 2011.

[3] Xu, Z., Wang, Z., Jing., N., He, L., Mu, R., and Wang, K., "Effects of Deposition Temperature on the Kinetics Growth and Protective Properties of Aluminide Coatings", Journal of Alloys and Compounds, Volume 632, pp. 238-245, 2015.

[4]

Tong, L., Dengzun, Y., and Chungen, Z., "Low-Temperature Formation of Aluminide Coatings on Ni-Base Superalloys by Pack Cementation Process", Chinese Journal of Aeronautics, Volume 23, No. 3, pp. $381-385,2010$

[5] Zhou, Y., Zhao, C., Hao, W., Wang, X., and Xiao, P., "The Oxidation Performance for Zr-Doped Nickel Aluminide Coating by Composite Electrodepositing and Pack Cementation”, Corrosion Science, Volume 123, pp. 103-115, 2017.

[6]
[7]

Chandio, A.D., Zhao, X., Chen, Y., and Xiao, P., “A Study of a $\beta$ NiAl Bondcoat Deposited onto CMSX-4 Superalloy for Thermal Barrier Applications Developments in Strategic Ceramic Materials", Ceramic Engineering and Science Proceedings, Volume 36, No. 8 , pp. 203, 2015 .

[8] Zhao, X., Cernik, B., Tang, C.C., Thompson, S.P., and Xiao, P., "Stress Evolution in a Pt-Diffused $\gamma / \gamma$ ' Bond Coat After Oxidation", Surface and Coatings Technology, Volume 247, pp. 48-54, 2014.

[9] Goward, G., "Protective Coatings for High Temperature Alloys State of Technology", Proceedings of Symposium on Properties of High Temperature Alloys with Emphasis on Environmental Effects, Volume 77, No. 1, 1976.

[10] Goward, G., and Boone, D., "Mechanisms of Formation of Diffusion Aluminide Coatings on Nickel-Base Superalloys", Oxidation of Metals, Volume 3, No. 5 , pp. 475-495, 1971.

[11] Xiang, Z., Burnell-Gray, J.S., and Datta, P.K., "Aluminide Coating Formation on Nickel-Base Superalloys by Pack Cementation Process", Journal of Materials Science, Volume 36, No. 23, pp. 5673-5682, 2001.

[12] Moskal, G., “Thermal Barrier Coatings: Characteristics of Microstructure and Properties, Generation and Directions of Development of Bond", Journal of Achievements in Materials and Manufacturing Engineering, Volume 37, No. 2, pp. 323-331, 2009.

[13] Sitek, R., Bolek, T., Dobosz, R., Plocinski, T., and Mizera, J., "Microstructure and Oxidation Resistance of Aluminide Layer Produced on Inconel 100 Nickel Alloy by CVD Method", Surface and Coatings Technology, Volume 304, pp. 584-591, 2016.

[14] Stringer, J., "Design of Coatings for High Temperature Corrosion Protection, in Surface Engineering: Surface Modification of Materials", Kossowsky, R., and Singhal, S.C., (Editors), pp. 561-587, Springer Netherlands, Dordrecht, 1984. 